\title{
A gramática escolar no contexto do uso lingüístico
}

\author{
Maria Helena de Moura Neves ${ }^{1}$ \\ UNESP - Araraquara/CNPq
}

\section{Abstract}

This article assesses the work with grammar at school according to the grammatical approach used and according to the insertion of that approach in an understanding of the real functioning of language. It is suggested, for instance, that the approach toward word classes should primarily take into account the level in which each class operates in the linguistic usage. 


\section{INTRODUÇÃO}

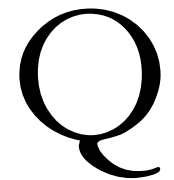

ualquer avaliação de uma diretriz impressa ao ensino de gramática passa necessariamente pela avaliação de dois parâmetros: primeiro, o que se entenda que seja a "gramática", que deva ser trabalhada nesse nível, e, segundo, o que se considere que seja, dentro do exercício da linguagem que os alunos ativam nas suas interlocuções, o foco do tratamento gramatical a empreenderse, isto é, o papel que tenha, na atividade escolar da análise lingüística, a consideração do real funcionamento da linguagem. Vamos partir da segunda para a primeira questão.

\section{REFLEXÕES SOBRE O FUNCIONAMENTO DA LINGUAGEM}

Para falar da natureza da linguagem, poderemos começar lembrando o famoso esquema do "circuito de comunicação", constante praticamente de todos os livros didáticos dos anos 80 . Nesse esquema, duas carinhas (emissor e receptor) apareciam face a face em duas pontas, e entre elas se registravam os demais componentes do circuito: canal, mensagem, código, etc.

Do ponto de vista do registro de dados, obtinha-se um esquema de fácil apreensão e de certa completude. Por exemplo, a física respondia pela ondas sonoras e sua transmissão; a psicologia sustentava a consideração das funções mentais; a própria ciência lingüística guiava a explicitação da utilização do código, pois não nos esqueçamos de que, desde os estóicos a ciência lingüística tem uma teoria dos signos (NEVES, 1987).

Entretanto, o real funcionamento da linguagem ficava por determinar, especialmente porque emissor e receptor permaneciam 
como dois bonequinhos, um em cada ponta, peças (artificialmente) aparatadas para, num momento, codificar, e, noutro momento, descodificar mensagens, isto é, ativamente, atribuir significados, e, passivamente, interpretar enunciados, aparentemente numa seqüência regular e mecânica.

Como esquema, aliás, era uma boa peça, aparentemente fechada; entretanto, como sugestão das funções que se cumprem no uso da linguagem - especialmente num tratamento dirigido à criança - era uma simplificação perigosa.

E por quê?

Em primeiro lugar, não se pode, nunca, perder de vista o fato de que a produção do enunciado resulta de uma complicada troca, que é a interação lingüística, nesse esquema desconsiderada, ou, pelo menos, minimizada. E, aí, o próprio modelo do circuito de comunicação tem de ser revisto. Em cada ponta não há mais uma careta, ou um bonequinho, nem podem as duas pontas do circuito ser vistas em molde idêntico: do lado do falante (um indivíduo com inserção social e com história), pesa a força da situação de comunicação, desde antes do planejamento da fala; na outra ponta, o interlocutor (também um indivíduo com inserção social e com história) não é um simples destinatário, pois o próprio direcionamento do enunciado, além de carregar a marca daquele que pratica o ato de fala, é regido pela imagem daquele que está na outra ponta.

Nesse complicado esquema, que é o da real interlocução, o falante insere no plano de seu enunciado a própria expectativa que ele supõe que seu ouvinte tenha sobre aquilo que ele vai dizer, e, ainda, a avaliação que ele tenha do potencial que seu ouvinte reúne para interpretar aquilo que ele possa dizer. Ao mesmo tempo, ele sabe que a interpretação que seu enunciado poderá gerar será também condicionada pela avaliação que seu interlocutor, ao receber o enunciado, faça da intenção que direciona a produção do seu enunciado, bem como do potencial informativo daquele indivíduo que ele espera que recupere tal intenção.

Concluindo: há que considerar um esquema de interação verbal mais rico - digamos assim - e mais real do que aquele que 
trata dos componentes desvinculados, que entram no circuito apenas como peças de uma máquina de codificar e descodificar.

Fala-se, aí, de uma situação interativa, porque é em interação que se usa a linguagem, nela é que se fala, sem se desprezar o fato de que a natureza da linguagem e sua relação com a categoria língua implicam não apenas atividade, mas também conhecimento e capacidade.

No uso lingüístico produzem-se textos. Há uma situação interativa absolutamente singular e conjuntural: há atos de fala. Isso ocorre, entretanto, no exercício de uma capacidade humana natural universal, e em uma determinada língua particular.

Ora o homem fala porque tem, em primeiro lugar, a capacidade de produzir linguagem, isto é, uma competência lingüística, que é o poder falar, mas também porque tem o domínio de uma língua particular historicamente inserida, isto é, um saber, que é o conhecimento de um idioma, e, ainda, porque se encontra em uma dada situação de uso, isto é, num evento comunicativo, em que se produz o discurso. Em suma, há o exercício da capacidade de falar (a linguagem), num falar historicamente inserido (numa dada língua) e num evento particular (na interlocução).

Voltando, nesse percurso, do fim para o começo, parto da unidade texto (que é o resultado de um discurso) e que é, pois, a unidade maior de funcionamento da linguagem, por isso, mesmo, a unidade privilegiada de reflexão e de análise. Afinal, os textos constituem o desenvolvimento das peças que o discurso constrói, mediante o saber de um idioma particular que uma tradição mantém equilibrado (embora sempre se possa falar em equilíbrio instável), e representando a documentação do exercício efetivo da capacidade de linguagem.

O que fica revelado é que o foco da busca está, na essência, nas funções da linguagem que se cumprem na produção textual.

Em última instância, o que se examina é a construção do sentido do texto, o que equivale a dizer que se acompanha o cumprimento das funções da linguagem, organizadas e regidas exatamente pela função textual, aquela que operacionaliza todas as demais que se possam ligar às atividades cognitivas e às interacionais. 
Diferentes correntes teóricas que estudam a linguagem vão privilegiar uma ou outra dessas visões do funcionamento da linguagem. Por exemplo, a capacidade humana da linguagem é o foco da investigação gerativista; a atenção às línguas particulares e a sua organização dentro de uma história e de um sistema constituem território da gramática descritiva, da filologia, da sociolingüística; a atuação lingüística abre leque para múltiplas investigações de análise do discurso; e sem esquecer que a questão da norma perpassa os dois últimos planos.

Essa proposição propicia que se traga à discussão um ponto essencial para a compreensão do fenômeno da linguagem (muito bem fundamentado nas propostas teóricas de COSERIU, especificamente no livro Competencia Linguistica: elementos de la teoría del hablar, original alemão de 1988, tradução espanhola de 1992). Como ser humano, o homem fala, ${ }^{2}$ e, portanto o falar tem dimensão universal: o homem, simplesmente, tem essa capacidade natural. Como elemento de uma comunidade, o homem fala uma língua particular, que necessariamente tem uma inserção histórica: é a língua x, e não a y, uma ou outra sempre representativa de uma tradição. E como indivíduo que vive situações de interlocução, o homem produz discurso sobre algo.

Resumindo: graças à sua capacidade de falar e graças à sua inserção histórica numa língua particular, o homem, efetivamente, atua lingüisticamente, ele produz discurso, ele constrói textos.

E onde entra a gramática? O que representa trabalhar com gramática, ou ensinar gramática?

Em primeiro lugar, tradicional e historicamente, e a rigor, a gramática que a escola "oferece" a seus alunos é a que está no bloco intermediário do nosso elenco inicial que considerou os aspectos do "falar": é a gramática de uma língua particular, no nosso caso, a gramática do português.

O que ocorre, entretanto, é que se considera cumprida a missão de oferecer aos alunos a "gramática" da língua portuguesa com o simples oferecer de parâmetros tradicionalmente instituídos: 
esquema de classes e subclasses, ou elenco de funções dentro da estrutura oracional, nem sempre avaliadas as relações entre as classes e as funções, relações, que, reconhecida e comprovadamente, não são biunívocas.

Dois problemas, pelo menos estão instaurados, e a eles voltarei: a metalinguagem sufoca a linguagem, o que é antinatural, e o nível a que se limita a análise (a oração) não é o nível ao qual a linguagem chega (que é o texto, construído em interação). Afinal, desconhecese que a gramática da língua particular (do português, no caso) deriva de uma capacidade natural (e, com ela, de fato, nada é necessário fazer), e, acima de tudo, se efetiva no uso, nas situações interlocutivas, na criação de textos.

Nem vou aqui buscar resolver, de um modo geral, o que se quer significar quando se usa o termo gramática. É possível ir desde a idéia de gramática como "mecanismo geral que organiza as línguas" até a idéia de gramática como "disciplina", e, neste último caso, não se pode ficar num conceito único, sendo necessária uma incursão por múltiplas noções, já que são múltiplos os tipos de "lições" que uma gramática pode fornecer, seja num modelo normativo puro, seja num modelo descritivo ou expositivo, seja num modelo gerativo, e assim por diante (NEVES, 2001, p. 28).

Entretanto nem os leigos nem os estudiosos têm sabido muito bem o que fazer com a gramática - e vou mais longe, com a disciplina Português - que, no fundo, revolta - ou pelo menos incomoda - todos aqueles que se sentam nos bancos escolares. E incomoda porque todos - ou quase todos - não entendem bem a que chegarão, com ela, ao final do "aprendizado". E a reflexão vai para a seguinte questão: Que esperam a sociedade e a família das aulas de Português nas escolas?

Em primeiro lugar espera-se que o aluno fale e escreva (especialmente, escreva) melhor. ${ }^{3}$ Ora, para essa finalidade, temos, tradicionalmente, duas possíveis soluções: adequação ao padrão culto ou adequação aos propósitos comunicativos, e ambos os resultados interessam: o primeiro representa falar e escrever de 
acordo com a norma padrão, o que, pela adequação sócio-cultural dos enunciados obtida, garante aprovação da sociedade, desempenho que pode ser pautado por uma gramática normativa de orientação segura; o segundo representa falar e escrever com compreensão do modo de organização dos enunciados bem como dos procedimentos que levam a uma adequada obtenção de sentidos (semanticamente acurados e pragmaticamente eficientes), desempenho que pode ser beneficiado com o procedimento reflexivo a que leva o trabalho com uma gramática de usos teoricamente sustentada. ${ }^{4}$

E volto aos três aspectos da linguagem que desdobrei no início das reflexões.

No primeiro aspecto que tratei, não cabe, por natureza, julgamento de mérito sobre um "falar melhor", já que o que está em questão é a capacidade lingüística do falante natural, aquela de simplesmente conseguir entender e fazer entender enunciados da língua materna. É uma "competência" cuja avaliação não envolve capacidade de aprimoramento ou condições de atingimento de padrões desejáveis.

No terceiro e último aspecto a que cheguei, também a escola não tem posto particularmente em questão o sucesso da interação, a pertinência da inserção do discurso na interlocução, a qualidade do texto, etc.

Resta o segundo aspecto, o que se refere à língua em particular de cada comunidade. Viciados na tradição, e sem entender o que é, realmente, "falar e escrever melhor", os pais querem registrada nos cadernos de seus filhos toda aquela sistematização, aquela hierarquização de entidades e subentidades, suas definições, seus exemplos, e, de quebra, uma série de exercícios, não importa quão mecânicos sejam. Está viva, no fundo, a idéia de que a exposição de paradigmas lingüísticos resgata a "boa linguagem", preserva padrões, evita violações e, a partir daí, protege contra as sanções da sociedade.

Afinal, nessa intrincada questão o que falta à escola?

Parece-me que, basicamente, e por incrível que pareça, o que falta à escola - em todos os níveis, inclusive na universidade - é 
conseguir considerar a linguagem em funcionamento, o que implica, em última análise, saber avaliar as relações existentes entre as atividades de falar, de ler e de escrever, todas elas práticas discursivas, todas elas usos da língua, nenhuma delas secundária em relação a qualquer outra, e cada uma delas particularmente configurada em cada espaço em que seja posta como objeto de reflexão.

Privilegiar a reflexão é exatamente a razão de se preconizar um tratamento da gramática que vise ao uso lingüístico. Não apenas o estudioso da língua portuguesa mas também o falante comum, conduzido na reflexão sobre o uso da linguagem, vai poder orientarse para a utilização eficiente dos recursos do processamento discursivo, e, a partir daí, chegar a uma sistematização dos fatos da língua legitimada pelo efetivo funcionamento da linguagem.

Um grande complicador interfere: a falta de considerar-se o que representa o uso da linguagem, a produção discursiva, a criação e recepção de textos. O que falseia a proposição pura e simples de um esquema como esse, apresentado como se refletisse a "comunicação" humana, é que o uso da linguagem é, basicamente, o cumprimento de funções. Não é necessário adotar-se particularmente nenhum dos elencos já propostos para as "funções da linguagem", como os de Bühler, Jakobson, Halliday (NEVES, 1997, p. 9-14) para assegurar que, no uso lingüístico, sempre se preenchem funções, e, que, especialmente na escola - por excelência um espaço de troca - é o real funcionamento da linguagem que tem de estar no centro das ações.

Queremos que as crianças falem e escrevam melhor? Ora, queremos que elas exerçam plenamente, sem bloqueios, sua capacidade natural de falantes, queremos que elas obtenham o domínio da língua particular que falam, o português, queremos que, nas suas atividades interlocutivas, elas consigam que as interpretações recuperem na melhor medida possível as intenções, já que essa é a meta de eficiência do processamento da interação verbal. (DIK, 1997) 


\section{O TRABALHO COM A GRAMÁTICA NA ESCOLA}

Entretanto qual é a avaliação que se tem feito da gramática do ensino tradicional, especialmente levada em conta a sua relação com o uso lingüístico?

Todos os estudiosos que se têm dedicado a avaliar o ensino vigente nas escolas têm acentuado o caráter absolutamente "ritual" de que o ensino tradicional de gramática se tem revestido:

- primordialmente se organizam atividades de simples rotulação, reconhecimento e subclassificação de entidades (classes ou funções);

- essas atividades se apóiam em uma prévia definição das entidades, oferecida como acabada, pretensamente inequívoca, absoluta;

- esse modo de tratamento das atividades, por si, implica que as entidades sejam tidas como discretas, com limites precisos, exatamente abrigados na definição oferecida;

- esse modo de tratamento das atividades significa, também, que a gramática é vista simplesmente como um mapa taxonômico de categorias, alheio à língua em funcionamento e organizado independentemente dos atos de interação lingüística, das funções que se cumprem no uso da linguagem, dos significados que se obtêm no discurso;

- configura-se, pois, o ensino da gramática como uma exposição e imposição de parâmetros, nos quais se devem simplesmente enquadrar, segundo instruções mecânicas, as entidades isoladas em textos-pretextos prontos, ou em orações artificiais especialmente construídas para tal exercitação;

- fica implicado, também, que a gramática acionada pelo falante de uma língua ao organizar a sua linguagem se esgota na estrutura da oração;

- com tudo isso, fica configurado, acima de tudo, que se prescinde de qualquer reflexão para falar de "gramática", e que se desconhece absolutamente o uso da linguagem quando se trata a "gramática" da língua. 
Podemos até permanecer apenas na consideração da gramática como parametrização de uma língua particular - a "gramática disciplina", a gramática de uma língua historicamente inserida - para defender que é partindo do texto que a análise lingüística se torna legítima, e, mesmo, possível.

Nem é necessário acentuar os aspectos que não representam o que tradicionalmente se tem entendido como "gramática", aqueles que constituem a "gramática organização", não a "gramática disciplina", e que são:

a) a gramática como um sistema de princípios que organiza as orações, sistema do qual têm posse todos os falantes nativos de uma dada língua, aquele natural conhecimento da língua materna que o falante aciona numa simples ligação entre esquemas cognitivos e linguagem, isto é, em decorrência simplesmente de a linguagem ser uma das manifestações do funcionamento da mente humana (a capacidade natural de linguagem, a competência lingüística);

b) a gramática como a extensão da competência do falante à organização das peças de interação, seja em textos continuados seja em peças em co-autoria (a produção de discurso na interlocução, a competência comunicativa).

No aspecto a) - a competência lingüística - temos a parte "computacional" da linguagem: o "programa" sempre "roda", porque nunca um falante natural viola o sistema; todo falante é competente, ele nunca ignora as restrições ao sistema, e, nesse sentido, ele não tem nada que aprender com algum ensino particular.

No aspecto b) - a produção de discurso na interlocução - o território é o das escolhas (NEVES, 2002, p. 80), portanto da "adequação", onde se calibra a "qualidade" do texto, o que depende de uma reflexão sobre os usos lingüísticos, sobre os (bons) efeitos de sentido, sobre as (eficientes) peças lingüísticas naquele particular evento de interlocução.

A que se chega, afinal? Ao fato de que não é a homogeneidade que se tem de buscar no exercício de uma atividade reflexiva sobre 
a linguagem; pelo contrário, a heterogeneidade é constitutiva da linguagem, pois a língua é um sistema eminentemente variável.

A partir daí, a perspectiva direcionadora do tratamento escolar da linguagem seria, a princípio, a rejeição de moldes, sejam eles de desempenho, guiado por submissão estrita a normas lingüísticas consideradas legitimadas, sejam eles de organização de entidades metalingüísticas, guiada por submissão estrita a um paradigma e suas exemplificações, o qual, excluindo outras formas, veladamente constitui uma organização modelar, e, portanto, diretiva.

A consideração da linguagem para a qual a sociolingüística nos preparou estabelece, irrefutavelmente, que, no funcionamento da linguagem em uma comunidade, não é natural que os padrões se imponham ao uso, mas que o uso estabeleça padrões, os quais, obviamente, do ponto de vista sócio-cultural, são submetidos a uma avaliação, já que diferentes usos hão de ser adequados a diferentes situações de uso.

Entretanto, a grande parte das lições gramaticais que os livros didáticos oferecem desconhece variação e mudança, e desconhece, principalmente, a ampla faixa de liberdade que o falante tem, no uso da língua, para compor seus enunciados. Tudo se diz, nas lições de gramática, como se houvesse um conjunto de paradigmas (esquemas) que, conhecidos, levassem a que se consiga usar (adequadamente) a língua e se logre dizer (bem) o que tem de ser dito.

Senão, vejamos alguns exemplos:

a) O funcionamento de algumas classes de itens pode resolver-se satisfatoriamente no nível da oração:

- é evidente que é nos limites da predicação que o verbo, por exemplo, determina sua estrutura argumental (os papéis semânticos, como Agente, Destinatário, etc., e - postos em perspectiva esses papéis semânticos - as funções sintáticas, como sujeito, objeto indireto, etc.).

- na contraparte disso, dentro da oração também se resolvem os papéis e as funções dos substantivos (mais especificamente, das expressões ou sintagmas que têm por núcleo um substantivo). 
Entretanto, dos sintagmas, ou expressões que têm por núcleo um substantivo também participam elementos de outra natureza, por exemplo alguns referenciadores de que se tratará logo adiante, em b).

b) Por outro lado, o funcionamento de outras classes de itens só se resolve - e, na verdade, só "começa" a resolver-se - em nível que "desconhece", que extrapola a organização oracional:

- pronomes pessoais de terceira pessoa (ele, ela, etc.), embora da mesma esfera semântica que os substantivos (argumentos / participantes da estrutura argumental das predicações: Agente, Destinatário, sujeito, objeto indireto, etc.), só se resolvem semântica e gramaticalmente se se põe em consideração seu papel de referenciadores, isto é, se se executa a instrução de busca de referente - em qualquer ponto do texto, ou no contexto - que eles instruem com a sua simples presença;

- do mesmo modo, demonstrativos, artigos definidos e possessivos, embora tenham sua função interna ao sintagma nominal (adjuntos adnominais), só podem ser "interpretados", só podem ter sua "gramática" resolvida se se põe em consideração o seu papel de referenciação textual ou situacional, se se atende àquela mesma instrução de busca que transcende os rígidos limites da estruturação sintática, isto é, os limites da oração. E é assim que eles dão aos sintagmas em que ocorrem - que têm um substantivo como núcleo - uma função e uma dimensão textuais inequívocas.

A avaliação do papel textual dos sintagmas nominais pode ser, numa boa direção, empreendida verificando-se o tratamento das funções argumentais que eles cumprem, mais especificamente examinando-se o modo como é tratado o preenchimento da função sujeito nos exercícios escolares, e cotejando esse tratamento com o que representa uma escolha, ou outra, do elemento que funciona como sujeito nos textos usados como mote para os exercícios propostos. Parto de exercícios porque acredito que a exercitação é 
o ponto revelador por excelência não apenas dos procedimentos como também do suporte teórico que conduz as reflexões. ${ }^{5}$

A primeira verificação é que o termo sujeito é costumeiramente tratado nas escolas em orações observadas avulsamente, como unidades auto-suficientes (mesmo que retiradas de textos produzidos), e com vistas apenas a uma classificação mecânica, operada com base em indícios superficiais e não relevantes, não se pondo em questão a dinâmica do texto e a organização referencial do discurso implicadas na escolha do modo de expressão do sujeito.

Aqui vai transcrito um exercício encontrado em livro didático (exercício que se encabeça por duas definições, a de sujeito e a de predicado), assim elaborado:

Termo de que se fala alguma coisa $=$ sujeito .

$\mathrm{O}$ que se fala do sujeito $=$ predicado .

Classifique o sujeito:

(1) Caraíbas têm cabeça oca.

(2) Deviam ter aprendido lições.

(3) A caça e o peixe também fugirão.

A resposta pretendida é que, no caso (1), se diga que caraíbas é o sujeito (expresso) simples da oração, que, no caso (2), se diga que o sujeito da oração (de deviam ter aprendido) é oculto. Ora, uma atenção mínima para o processo textual de referenciação requereria outra lição inicial (não as definições que encabeçam o exercício), ${ }^{6}$ e levaria ao tratamento da questão por outros caminhos. O primeiro procedimento seria manter as frases no texto, já que o chamado "sujeito oculto" da segunda frase ${ }^{7}$ nada mais representa do que o recurso a uma elipse do sujeito (permitida em nossa língua, mas não em outras, como o inglês, o francês, o alemão) por efeito da organização textual: o enunciador escolheu um "vazio", um "zero" ( $\varnothing)$ nesse ponto do enunciado porque esse zero é suficiente para manter a adequada remissão, na busca de informação, como se comprova observando o texto do qual a frase foi retirada, texto que se encontra transcrito algumas páginas antes do exercício proposto,${ }^{8}$ mas que, na proposição do exercício é absolutamente esquecido e ignorado: 


\section{A profecia}

Caraíbas têm cabeça oca. $\varnothing$ Deviam ter aprendido muitas lições com o povo filho da terra e não souberam enxergar, nem ouvir, nem sentir. E $\varnothing$ sofrerão por isso.

Dia virá em que $\varnothing$ ficarão com sede, muita sede, e $\varnothing$ não terão água pra beber: os rios e lagoas e valos e regatos e até a água da chuva estarão sujos e pobres. E $\varnothing$ chorarão. E $\varnothing$ continuarão com sede porque a água do choro é salgada e amarga... [ ]

Como se vê, a elipse do sujeito (ou seja, o "zero") também é suficiente para a recuperação do objeto-de-discurso caraíbas nas cinco orações seguintes: sujeito de sofrerão, de ficarão, de não terão, de chorarão e de continuarão.

O mesmo não se pode dizer das orações que vêm a seguir no texto, nas quais se introduzem novos tópicos oracionais, novos temas:

[ ] O tempo da fome também virá. E a terra estará seca, o chão duro. As sementes do milho e a mandioca não mais nascerão verdes, alimentando a esperança de quarups ao redor do fogo com muita comida e bebida. A caça e o peixe também terão fugido ou morrido. E a fome apertará o estômago do caraíba e ele não poderá comer nem sua riqueza, nem sua terra nua e estéril.

Os dias serão sempre mais quentes. E quando o caraíba procurar uma sombra como abrigo, descobrirá que a terra não tem mais árvores.

As noites serão escuras e frias. Sem lua, sem estrelas. E sem fogueiras quentes.

E o caraíba, o bomem-branco, chorará. E quando acordar de sua imensa estupidez será tarde, muito tarde.

Eu, Tamãi, o velho pajé, falei. (ZOTZ, 1979, p.14, grifo nosso)

É exatamente por isso que, no caso da frase (3) do exercício, o que se espera é que o aluno responda que o sujeito é (expresso) composto (a caça e o peixe). Ocorre que, quando uma oração se constrói com o chamado sujeito "expresso" representado por uma expressão que tem substantivo como núcleo, tal fato tem razões discursivo-textuais: ${ }^{9}$ não é porque alguém decidiu, num determinado 
momento, contemplar uma das "subclasses" de sujeito da Nomenclatura Gramatical Brasileira (sujeito oculto, sujeito simples, etc.), mas porque, nesse ponto do enunciado, um sintagma nominal se faz necessário para operar uma descrição, imprescindível à configuração de uma entidade no fluir da informação, o que não se obtém com $\varnothing$ ("sujeito oculto") e nem mesmo com ele, ela, eles ou elas (sujeito expresso por pronome pessoal).

Desse modo, também na escolha entre sujeito "expresso" por sintagma nominal e sujeito "expresso" por pronome pessoal interfere a organização tópica, já que - como eu já disse em outro estudo (NEVES, 2002, p. 226) - ninguém procede, no caso "como se estivesse simplesmente diante de um teste de múltipla escolha”. Obedecidas as restrições inerentes ao sistema (por exemplo, a impossibilidade de um pronome oblíquo átono, como lhe, ou de um pronome pessoal preposicionado, como dele, na posição de sujeito), o falante procede a uma escolha comunicativamente adequada e usa um sintagma nominal para ocupar a casa de sujeito num ponto do enunciado em que se reclama a especificação descritiva (por um núcleo nome) da entidade a que se faz referência, que é o caso, nesse texto, de o tempo da fome, a terra, as sementes de milho e a mandioca, a caça e opeixe, a fome, os dias, o caraíba, as noites, o homem branco. E escolhe, diferentemente, um pronome pessoal de terceira pessoa em algum ponto do enunciado em que é necessária uma referenciação pessoal - e por isso não ocorre zero, ou elipse, mas ocorre ele ou suas flexões -, mas não é necessária a especificação descritiva da entidade referenciada (que um nome, um substantivo faria), como na segunda oração desta frase: "E a fome apertará o estômago do caraíba e ele não poderá comer nem sua riqueza, nem sua terra nua e estéril." (ZOTZ, 1979, p.14, grifo nosso).

Para que um estudante reflita sobre os recursos que a língua lhe oferece para melhor desempenho, o que proponho como absolutamente imprescindível é que se propicie uma reflexão sobre a funcionalidade das escolhas que o falante faz e sobre os resultados de sentido que cada escolha desencadeia. Não há uma substituição 
mecânica de nome por pronome, ou de pronome por zero, operada aleatoriamente, como sugerem exercícios que também encontrei propostos, do tipo de:

Substitua a expressão grifada por um pronome pessoal:

1. Caraíbas têm cabeça oca.

2. O tempo da fome também virá.

3. A caça e o peixe também terão fugido.

A simples recolocação das frases no texto (de onde nunca deveriam ter saído) mostra que essas substituições não são possíveis, sem que o texto fique mutilado, destruído, completamente prejudicado, como se pode ver nesta simulação, que dever ser comparada com o texto original há pouco transcrito.

\section{A profecia \\ (Simulação)}

Eles têm cabeça oca. Deviam ter aprendido muitas lições com o povo filho da terra e não souberam enxergar, nem ouvir, nem sentir. E sofrerão por isso.

(.....................).

Ele também virá. Ela estará seca, o chão duro. Elas não mais nascerão verdes, alimentando a esperança de quarups ao redor do fogo com muita comida e bebida. Eles também terão fugido ou morrido. E ela apertará o estômago do caraíba, e ele não poderá comer nem sua riqueza, nem sua terra nua e estéril.

A simples observação das escolhas, no texto original, mostra evidentemente que a eleição de um ou outro tipo de elemento para sujeito tem motivações particulares que precisam ser avaliadas não apenas para que se possa fazer a boa leitura do texto como também para tornar claros os efeitos da escolha, e, por aí, ter subsídios para pautar o bom desempenho, nas possíveis situações de produção textual. Observe-se que os efeitos particulares da escolha de um sintagma nominal para a posição de sujeito são tanto mais evidentes quanto mais se levar em conta que o sintagma nominal não é votado prioritariamente para ser o tópico, e, conseqüentemente, o sujeito da oração. 
A observação de um outro texto, também presente em livro didático, ilustra bem a necessidade de se tratar a questão como algo mais do que, simplesmente, uma "subclassificação" de sujeito, mais especificamente, ilustra a necessidade de se tratar a questão como de produção de linguagem, de uso lingüístico.

\section{Direito de ter direitos}

É muito importante entender bem o que é cidadania. $\varnothing$ É uma palavra usada todos os dias e tem vários sentidos. Mas hoje $\varnothing$ significa, em essência, o direito de viver decentemente.

Cidadania é o direito de ter uma idéia e poder expressá-la. $\varnothing$ É poder votar em quem quiser sem constrangimento. $\varnothing$ É processar um médico que cometa um erro. $\varnothing$ É devolver um produto estragado e receber o dinheiro de volta. $\varnothing$ É o direito de ser negro sem ser discriminado, de praticar uma religião sem ser perseguido. (DIMENSTEIN, 1999, p. 29-30, grifo nosso)

Ora, por uma ou por outra razão, em nenhum dos casos, no lugar do zero (ou seja, do tal de "sujeito oculto") poderia ocorrer ela. Em geral eram possíveis ao autor do texto duas opções, a referência com zero (que foi a opção escolhida) ou com cidadania, que é um sintagma nominal sem determinante, por isso mesmo de efeito referencial diferente do pronome pessoal ela.

É, afinal, a evidência de que a gramática da língua se resolve na produção textual, e vice-versa.

\section{CONSIDERAÇÕES FINAIS}

O ponto central que se oferece à reflexão, na observação do tratamento da gramática nas escolas, é que esse tratamento se tem feito como se gramática fosse alguma entidade postiça a que só teremos acesso se sairmos dos textos, isto é, se abstrairmos os usos, o que é exatamente o que não pode ocorrer. Há lições fundamentais sobre o funcionamento da linguagem que a escola esquece:

a) a cada instância de utilização da língua se ativa a gramática e, portanto, a gramática (como organização da fala) se explicita a partir do uso lingüístico; 
b) a gramática que o falante aciona para organizar sua linguagem não se esgota em estruturas menores, nem mesmo no período (para usar o termo de nossa Nomenclatura Gramatical Brasileira), o qual é limite, apenas, de uma determinada organização estrutural;

c) é irreal e afuncional qualquer amoldamento absoluto de entidades gramaticais discretamente isoladas e a priori resolvidas; a gramática de uma língua em funcionamento não se faz de regras absolutas, com condições autônomas e absolutas de aplicação;

d) a redução das atividades com gramática a uma exercitação de metalinguagem, com pura catalogação irrefletida e mecânica de entidades é não só ineficiente, mas, ainda, contraproducente, porque leva a uma descrença final sobre a validade da investigação gramatical;

e) sob pena de perder toda legitimidade, a disciplina gramatical escolar não pode alhear-se do real funcionamento da linguagem, e limitar-se ao oferecimento de um simples mapa taxonômico de categorias, definidas em planos isolados; fica incluída a legitimação do tratamento da língua-padrão, já que é real a necessidade de os cidadãos adequarem seus enunciados aos diferentes contextos sócio-culturais de interação.

Assim, são lições a tirar de nossas reflexões:

a) nenhum falante de uma língua precisa primeiro estudar regras de aplicação que uma disciplina gramatical lhe oferece, para depois ser falante competente de sua língua; a ativação natural da gramática da língua é a simples e exata medida da ligação entre esquemas cognitivos e capacidade de enunciação (que envolve capacidade lingüística e capacidade social).

b) a gramática como disciplina escolar terá de entender-se como explicitação do uso de uma língua particular historicamente inserida, e, por aí, do próprio funcionamento da linguagem - em todos os seus ângulos, inclusive o social - com base em muita reflexão sobre dados, o que exclui qualquer atividade de encaixamento em moldes que prescindem das ocorrências naturais e ignoram zonas de imprecisão e/ou de oscilação, verdadeiras testemunhas do equilíbrio instável 
que caracteriza a própria vida da língua, a sua constante adaptação segundo a força das constantes pressões - tanto internas como externas - que se exercem sobre os usos (DU BOIS, 1985).

Afinal, sabemos que, em ciência, uma simplificação a qualquer custo pode significar barateamento, mistificação, falsidade, e não é com a linguagem nossa de cada dia que vamos ter o direito de fazer isso, fingindo que ela está mumificada e que é assim que dela nos servimos. E nem é no espaço da escola, institucionalmente alocado para o desenvolvimento das capacidades do indivíduo, que, justamente no ensino da língua pátria, vamos contentar-nos com recortes facilitadores que, bloqueando o bom uso lingüístico, mutilam o eficiente cumprimento de funções que a linguagem de todos e de cada um tem de atingir.

\section{NOTAS}

${ }^{1}$ Departamento de Lingüística - Faculdade de Ciências e Letras, UNESP / CNPq. Araraquara, SP, Brasil (mhmneves@techs.com.br).

${ }^{2}$ Aliás, como já dizia Aristóteles, sem linguagem não haveria sociedade política (ARISTOTE, 1968, I, 2, 1253a).

${ }^{3}$ Verifiquei isso em pesquisa de campo com 170 professores (NEVES, 1990). A situação real é a seguinte: $100 \%$ dos professores ensinam gramática; a finalidade pretendida é, sempre e declaradamente, ensinar a "escrever melhor"; faz-se uma compartimentação entre as lições de gramática, de leitura e de redação; ensinase, basicamente, a colocar rótulos em palavras e a classificar e subclassificar palavras; no final da avaliação de seu trabalho, os professores não sabem dizer para que serviu o ensino de gramática.

${ }^{4}$ Entretanto, na prática, há um conflito com a gramática ensinada, porque ela nem é normativa (para guiar a correção) nem vai ao texto (para, de fato, ensejar um melhor desempenho no uso lingüístico). O que verifiquei na pesquisa citada (NEVES, 1990) é que os professores foram despertados para uma crítica dos valores da gramática tradicional, e, por isso, têm procurado dar aulas de gramática não-normativa, o que os leva a que as aulas de gramática sejam reduzidas a uma simples exposição de taxonomia. Verificam eles que a gramática que ensinam não está contribuindo para a finalidade pretendida de "escrever melhor", mas mantêm as aulas sistemáticas de gramática como um ritual imprescindível à legitimação de seu papel. 
${ }^{5} \mathrm{O}$ exame dos exercícios que os professores propunham constituiu a chave para minhas conclusões, por exemplo, quando empreendi as investigações que estão no meu livro Gramática na escola (1990).

${ }^{6}$ Cabe observar que, na verdade, as definições oferecidas nem são as definições de sujeito e de predicado, mas são definições de entidades do fluxo de informação: a primeira, da unidade informativa a que podemos chamar tema, ou tópico oracional, e a segunda, da parte oracional a que podemos chamar rema, ou comentário. Isso já é lição da Escola de Praga, mas a escola ignora (ILARI, 1986, p. 53-61; NEVES, 1997, p.16-19).

${ }^{7} \mathrm{E}$, pelo treino que sabemos que se faz nas escolas, podemos até temer que nem a essa resposta o aluno chegue, decidindo-se pela resposta "sujeito indeterminado".

${ }^{8}$ Vou inserir a marca Ø para indicar os pontos em que o autor optou por um "zero" (uma elipse) na posição de sujeito.

9 Lembre-se de que, em estudos sobre o que se tem chamado "estrutura argumental preferida" (DU BOIS, 1985, 1987; ENGLAND \& MARTIN, s/d; KUMPF, 1992; ASHBY \& BENTIVOGLIO, 1993; BENTIVOGLIO, 1994; e, para o português, DUTRA, 1987; NEVES, 1994 e PEZATTI, 1996), tem-se verificado que é muitíssimo mais freqüente a ocorrência de objeto direto do que a de sujeito de oração transitiva com sintagma nominal, exatamente porque a posição de sujeito é, em geral, de informação já conhecida, sendo, por isso mesmo, raríssima a ocorrência de SN simultaneamente nas duas posições, a de sujeito e a de objeto direto. E, de fato, no texto do qual se retiraram as frases do exercício, os sujeitos representados por sintagma nominal estão, na sua quase totalidade, em orações com verbos que não são transitivos diretos: (o tempo da fome) virá, (a terra) estará seca, (as sementes do milbo e a mandioca) nascerão, (a caça e o peixe) terão fugido ou morrido, (os dias) serão quentes, (o caraíba, o bomem branco) chorará.

\section{REFERÊNCIAS BIBLIOGRÁFICAS}

ARISTOTE. Politique. Texte établi et traduit par Jean Aubonnet. 2.ed. Paris: Les Belles Lettres, 1968, tome I.

ASHBY, W.; BENTIVOGLIO, P. Information flow in spoken French and Spanish: a comparative study. Washington, D.C: Georgetown University, 1993.

BENTIVOGLIO, P. Spanish preferred argument structure across time and space. D.E.L.T.A. v. 10, n. esp., p. 277-293, 1994. 
COSERIU, E. Competencia linguística. Elementos de la teoría del hablar. Tradução espanhola. Madrid: Gredos, 1992.

DIMENSTEIN, G. O cidadão e o papel-a infância, a adolescência e os Direitos Humanos no Brasil. 16.ed. São Paulo: Ática, 1999.

DU BOIS, J. Competing motivations. In: HAIMAN, J. (Ed.). Iconicity in syntax. Amsterdam: John Benjamins, 1985. p. 343-365.

. The discourse basis of ergativity. Language, n. 63, 1987, p. 805-855.

DUTRA, R. The bybrid S category in Brazilian Portuguese: some implications for word order. 1987. Mimeografado.

ENGLAND, N.; MARTIN, L. Issues in the applications of preferred argument structure analisys to non-pear stories. MS: Cleveland State University, s/d.

DIK, S. The theory of Functional Grammar 2. Ed. by K. HENGEVELD. Berlin/ New York: Mouton de Gruyter, 1997.

ILARI, R. Perspectiva funcional da frase portuguesa. Campinas: Ed. da UNICAMP, 1986.

KUMPF, L. Preferred argument in second language discourse: a preliminary study. Studies in Language. v. 16, n. 2, p. 369-403, 1992.

NEVES, M. H. M. A vertente grega da gramática tradicional. São Paulo: HUCITEC/ UNB, 1987.

. Gramática na escola. São Paulo: Contexto, 1990.

- A estrutura argumental preferida em inquéritos do NURC. 1994 Mimeografado.

. A gramática funcional. São Paulo: Martins Fontes, 1997.

. As gramáticas: o usuário e a norma. In: DIONISIO, A.; MENDONÇA, M.

(Org.). I Encontro sobre Gramáticas do Português - Conferências. Recife: Editora Universitária/UFPE, 2001, p. 28-46.

2002.

A gramática: bistória, teoria e análise, ensino. São Paulo: Ed. UNESP,

PEZATTI, E. G. Estrutural argumental e fluxo de informações. In: KOCH, I. G. V. (Org.). Gramática do Português falado. v. VI: Desenvolvimentos. Campinas: Ed. da UNICAMP/FAPESP, 1996, p. 275-299.

ZOTZ, W. Apenas um curumim. 12. ed. Rio de Janeiro: Nórdica, 1979. 